\title{
Expression of Ki 67 and human papilloma virus 16 with risk factors in cervical pre malignant and malignant lesions
}

\author{
Agarwal U. ${ }^{1}$, Chandra S. ${ }^{2}$, Barua $\mathrm{U}^{3}$, Shrivastava V. ${ }^{4}$ \\ ${ }^{1}$ Dr. Urvi Agarwal, Resident, ${ }^{2}$ Dr. Smita Chandra, Professor, ${ }^{3}$ Dr. Upasana Barua, Assistant Professor, ${ }^{4}$ Dr. Vikas \\ Shrivastava, Assistant Professor; ${ }^{1,2,4}$ authors are Department of Pathology and ${ }^{3}$ author is affiliated with Department of \\ Obstetrics and Gynaecology, Himalayan Institute of Medical Sciences, Swami Rama Himalayan University, Swami Ram \\ Nagar, Doiwala, Dehradun, Uttarakhand, India.
}

Corresponding Author: Dr. Smita Chandra, Professor, Department of Pathology, Himalayan Institute of Medical Sciences, Swami Ram Himalayan University, Swami Ram Nagar, Doiwala, Dehradun, Uttarakhand, India. E-mail: smita_harish@yahoo.com

\begin{abstract}
Introduction: The present study was conducted to assess immunohistochemical expression of Ki-67 and HPV 16 in premalignant and malignant lesions of cervix. It was also intended to study the risk factors which may be associated with these lesions in Uttarakhand state of India. Material and Method: The study including premalignant and malignant lesions of cervix diagnosed over period of one year. Immunohistochemical staining on paraffin blocks for all cases and controls were done for HPV 16 and Ki-67. Ki-67 score was quantified depending on the percentage of positive cells and was statistically analyzed in association with HPV expression. Results: The study included 50 cases of premalignant and malignant cervical lesions and 50 controls. 87.2\% of the HPV 16 positive cases were also positive for Ki-67 expression which was statistically significantly higher in comparison to controls. Ki-67 expression was negative in all the controls while $90 \%$ of cases showed positivity for Ki-67. The malignant lesions of cervix show a significantly higher grade of Ki67 expression in comparison to premalignant lesions ( $p$ value $<0.001$ ). Conclusion: Low socioeconomic and education status, smoking (either active or passive), early age of sexual contact and first conception with high parity were associated with increased risk of cervical premalignant and malignant lesions in this region of India. Ki-67 plays an important role in carcinogenesis of cervical cancer in association of HPV16. The increase of immunopositivity of Ki-67 with the severity of lesions suggests its use in stratification of premalignant and malignant lesions of cervix.
\end{abstract}

Keywords: Cervical cancer; Premalignant lesion; Ki-67; Human Papilloma virus

\section{Introduction}

According to GLOBOCAN 2018, worldwide cervical cancer is the 4th most common malignancy among females, with age standardized incidence rate of 13.1 per 100,000 and mortality rate of 6.9 per 100,000 population [1]. However, the occurrence of cervical cancer is higher in Indian females with age standardized rate of 14.7 and mortality of 9.2 per 100,000 population [1]. Human papilloma virus (HPV) infection is amongst the foremost causes of cervical cancer.

The spectrum of morphological lesions caused by HPV cervical infection is large, ranging from normal to precancerouslesions (cervical intraepithelial neoplasia) and finally leading to invasive cancer. Among the 15 high risk HPVs, HPV-16 is the most predominant form

Manuscript received: $4^{\text {th }}$ May 2019

Reviewed: $14^{\text {th }}$ May 2019

Author Corrected: $20^{\text {th }}$ May 2019

Accepted for Publication: $23^{\text {rd }}$ May 2019 and is known to contribute to $60 \%$ of the total cervical cancer cases [2].Viral proteins E6 and E7 are the main viral components contributing to carcinogenesis, mainly via interfering with the tumor suppressor genes ( $p 53$ and $\mathrm{Rb}$ ) which leads to uncontrolled cell cycle progression by surpassing the G1 phase arrest. This in turn, alters the expression profiles of proliferation markers such as Ki-67[3]. Ki-67, a nuclear proliferation marker is encoded by MKI 67 gene in humans [4]. In CIN lesions, its expression is proportional to the extent of abnormally proliferating cells in the stratified squamous epithelium [5]. The present study was therefore done to assess the immunohistochemical expression and correlation of Ki-67 with HPV 16 in premalignant and malignant lesions of cervix. It was also intended to study the various risk factors which may be associated with these lesions in Uttarakhand, a north Himalayan state of India. 


\section{Material and Method}

Setting and type of study: Cross sectional prospective study was conducted in the department of Pathology in the Himalayan Institute of Medical Sciences, Dehradun situated in Uttarakhand state of India over a period of 1 year from January 2017 to December 2017 after obtaining written informed consent and approval from institutional ethics committee.

Sample size: 100 samples were including for statistical purpose by convenient sampling. $100 \%$ enumeration of samples from all eligible study subjects reported during the study period of one year was considered.

Sample methods: All consecutive cases diagnosed with cervical premalignant and malignant lesions were included in the study.

\section{Selection of Subject}

Inclusion Criteria: Patients diagnosed with chronic cervicitis, cervical intraepithelial neoplasia (CIN) I, II, III and cervical carcinoma diagnosed on histopathological examination of cervical biopsies/ total hysterectomy specimen.

Exclusion criteria: Patients of benign neoplasm of cervix including papilloma, condyloms, polyp and leiomyoma.

\section{Study protocol}

1.All the relevant clinical details along with socioeconomic status, dietary habits, smoking status, sexual and obstetrical history were noted for every case after written informed consent in case reporting form.

2.Cervical biopsy tissue/total hysterectomy specimens were received from the department of Gynaecology as per standard procedure.

\section{Original Research Article}

3.Histopathological tissues were collected and the tissue fixation was performed in $10 \%$ formalin solution, grossed and processed according to the Standard Procedure being followed in the department.

4.Histopathological diagnosis of cervical lesions was made according to WHO classification of cervical tumors

5.After histopathological diagnosis, immunohistochemical analysis for HPV 16 (Bio Genex, California, USA) and Ki-67 (Bio Genex, California, USA) was performed on paraffin embedded, formalin fixed biopsy sections as per standard procedure and instructions given by manufacturers.

6. HPV 16 immunostained slides were reported as negative or positive depending on percentage of cells showing immunopositivity ( $<5 \%$ cells-negative, 5$100 \%$ cells - positive). Ki-67 score was quantified depending on the percentage of positive cells [6] Negative: $<5 \%$ of Ki-67 positive cells, Grade 1: $5-25 \%$ of Ki-67 positive cells, Grade 2: $26-50 \%$ of Ki-67 positive cells, Grade 3: $>50 \%$ of Ki-67 positive cells.

Data Management \& Statistical Analysis: All the collected data was documented in an excel sheet and SPSS version 22 was used for statistical analysis.

The expression of Ki-67 and of HPV 16 in premalignant and malignant lesions of cervix was compared to that of controls by using Fisher exact test.

The association between the expression of $\mathrm{Ki}-67$ and HPV 16 was calculated in premalignant and malignant cervical lesions by Chi Square test.

\section{Results}

The study included total 50 cases and out of which 9 cases were premalignant and 41 cases were malignant. 50 controls were also included in the study. The mean age of total cases was $51.5 \pm 12.3$ years with range of 26-70 years and maximum number of cases was in the age group of $41-50$ years (28\% of total cases). The mean age of cases with premalignant lesions was $40 \pm 10.83$ years and with malignant lesions was $53.9 \pm 11.28$ years. Table 1 shows the various socio-demographic and reproductive characteristics of the cases and controls in the study. It showed that there was significantly higher rate of illiteracy, smoking and low socio-economic status in cases in comparison to controls. Table 2 shows the clinical complaints of the cases showing that vaginal discharge was the most common complaint. Table 3 shows the immunohistochemical expression of HPV 16 and Ki-67in cases and controls.It shows that Ki-67expression was negative in all the controls while $90 \%$ of cases showed positivity for Ki-67. Table 4 shows the immunoexpression of Ki-67 and HPV 16 in different histopathological types of premalignant and malignant lesions (Figure 1). There was no statistically significant difference in HPV 16 positivity between LSIL and HSIL and between HSIL and invasive carcinoma. However, with regard to Ki-67 expression, maximum number of premalignant cases $(66.7 \%)$ showed grade 1 expression for Ki-67 and maximum number of malignant cases (68.3\%) showed grade 3 expression for Ki-67. Grade 3 Ki-67 expression was seen in none of the premalignant cases. The malignant lesions of cervix show a significantly higher grade of Ki-67 expression in comparison to premalignant lesions ( $\mathrm{p}$ value $<0.001$ ). 


\section{Original Research Article}

Table-1: Socio-demographic and reproductive characteristics of the cases and controls.

\begin{tabular}{|c|c|c|c|}
\hline Characteristics & $\begin{array}{c}\text { Cases Number } \\
\text { (Percentage of total } \\
\text { cases) }\end{array}$ & $\begin{array}{c}\text { Controls Number } \\
\text { (Percentage of total controls) }\end{array}$ & p value \\
\hline $\begin{array}{l}\text { Education Status } \\
\text { Illiterate }\end{array}$ & $35(70 \%)$ & $22(44 \%)$ & $<0.05$ \\
\hline $\begin{array}{l}\text { Smoking Status } \\
\text { Active smokers } \\
\text { Passive smokers } \\
\text { Non smokers } \\
\text { Socioeconomic status } \\
\text { Low socioeconomic } \\
\text { Middle socioeconomic }\end{array}$ & $\begin{array}{l}24(48 \%) \\
38(76 \%) \\
12(24 \%) \\
42(84 \%) \\
8(16 \%)\end{array}$ & $\begin{array}{l}13(26 \%) \\
20(40 \%) \\
30(60 \%) \\
28(56 \%) \\
22(44 \%)\end{array}$ & $\begin{array}{l}<0.001 \\
<0.001\end{array}$ \\
\hline $\begin{array}{l}\text { Age of first sexual contact } \\
\text { Years (Mean } \pm \text { SD) } \\
\text { Age of first conception } \\
\text { Years (Mean } \pm \text { SD) } \\
\text { Parity } \\
\text { Multiparous (Parity }>=5 \text { ) }\end{array}$ & $\begin{array}{c}18.76 \pm 2.25 \\
20.86 \pm 2.25 \\
32(64 \%)\end{array}$ & $\begin{array}{c}20.7 \pm 2.12 \\
22.5 \pm 2.27 \\
6(12 \%)\end{array}$ & $\begin{array}{l}<0.001 \\
<0.05 \\
<0.001\end{array}$ \\
\hline $\begin{array}{l}\text { Contraceptive Method used } \\
\text { Nil } \\
\text { Oral pills, barrier method, } \mathrm{Cu} \mathrm{T}\end{array}$ & $\begin{array}{l}34(68 \%) \\
16(32 \%)\end{array}$ & $\begin{array}{l}23(46 \%) \\
27(54 \%)\end{array}$ & $<0.05$ \\
\hline $\begin{array}{l}\text { Dietary habits } \\
\text { Vegetarian } \\
\text { Mixed (Vegetarian and non } \\
\text { vegetarian) }\end{array}$ & $\begin{array}{l}31(62 \%) \\
19(38 \%)\end{array}$ & $\begin{array}{l}25(50 \%) \\
25(50 \%)\end{array}$ & 0.3 \\
\hline
\end{tabular}

Table-2 : Clinical Complaints of the cases.

\begin{tabular}{|c|c|c|}
\hline Clinical complaints & Number of cases & Percentage (\%) \\
\hline Vaginal Discharge & 34 & 68 \\
\hline Bleeding Per Vaginum & 32 & 34 \\
\hline Pain Abdomen & 17 & 4 \\
\hline Heaviness in Vagina & 2 & 4 \\
\hline Itching & 2 & 2 \\
\hline
\end{tabular}

Table-3: Immunohistochemical expression of HPV 16 and Ki-67in cases and controls.

\begin{tabular}{|l|c|c|c|c|} 
& HPV 16 Positive & HPV 16 Negative & Ki-67 Positive & Ki-67 Negative \\
Cases & $39(78 \%)$ & $11(22 \%)$ & $45(90 \%)$ & $5(10 \%)$ \\
\hline Controls & $2(4 \%)$ & $48(96 \%)$ & $0(0 \%)$ & $50(100 \%)$ \\
\hline
\end{tabular}




\section{Original Research Article}

Table-4: Immunoexpression of HPV 16 and Ki-67 in cervical premalignant and malignant lesions.

\begin{tabular}{|l|c|c|c|c|c|}
\hline Histopathological Diagnosis & $\begin{array}{c}\text { Number } \\
\text { of Cases }\end{array}$ & $\begin{array}{c}\text { HPV 16 } \\
\text { Positive }\end{array}$ & $\begin{array}{c}\text { HPV 16 } \\
\text { Negative }\end{array}$ & Ki-67 Positive & $\begin{array}{c}\text { Ki-67 } \\
\text { Negative }\end{array}$ \\
\hline LSIL & 7 & 7 & 0 & 4 & 3 \\
\hline HSIL & 2 & 2 & 0 & 2 & 0 \\
\hline WD SCC & 1 & 1 & 0 & 1 & 0 \\
\hline MD SCC & 21 & 17 & 4 & 20 & 1 \\
\hline PD SCC & 5 & 4 & 1 & 5 & 0 \\
\hline Basaloid SCC & 5 & 1 & 4 & 4 & 1 \\
\hline MDSCC with Sarcomatoid change & 1 & 1 & 0 & 1 & 0 \\
\hline MDSCC papillary variant & 2 & 2 & 0 & 2 & 0 \\
\hline Adenocarcinoma & 5 & 3 & 2 & 5 & 0 \\
\hline Small Cell Carcinoma & 1 & 1 & 0 & 1 & 5 \\
\hline Total & 50 & 39 & 11 & 45 & 0 \\
\hline
\end{tabular}

LSIL, Low Grade Squamous Intraepithelial Lesion; HSIL, High Grade Squamous Intraepithelial Lesion; WD SCC, Well Differentiated Squamous Cell Carcinoma; MD SCC, Moderately Differentiated Squamous Cell Carcinoma; PD SCC, Poorly Differentiated Squamous Cell Carcinoma; SCC, Squamous Cell Carcinoma

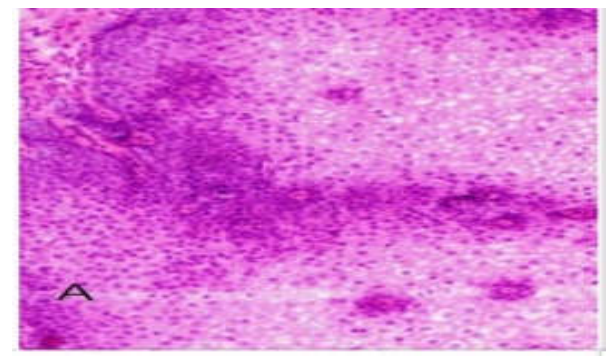

Figure 1: A) Histopathological section showing HSIL (HE; x10),

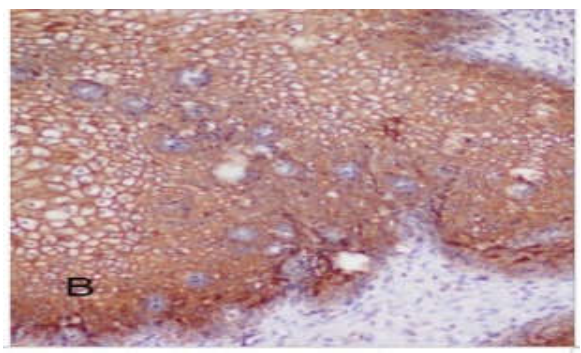

B) Section showing positive immunohistochemical expression of HPV in HSIL (HPV; x10),

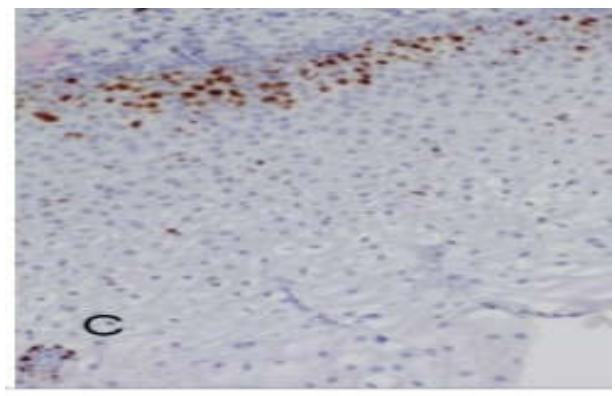

C) Section showing grade 1+ (positive) immunohistochemical expression of Ki-67 in HSIL (Ki-67; x10) 


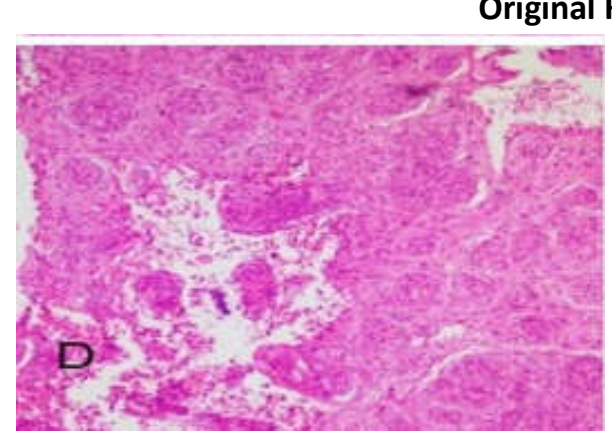

D) Histopathological section showing moderately differentiated squamous cell carcinoma (HE; $\mathbf{x 4})$

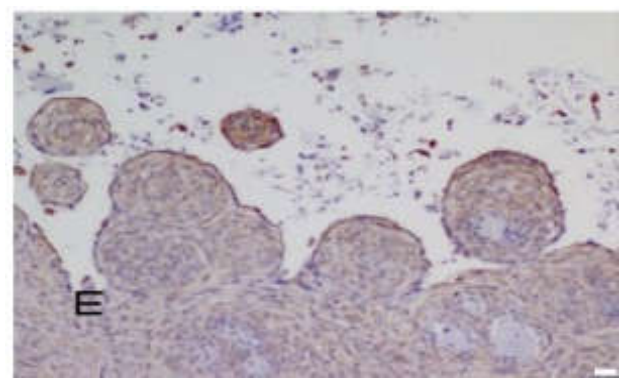

E) Section showing positive immunohistochemical expression of HPV in moderately differentiated squamous cell carcinoma (HPV; x10),

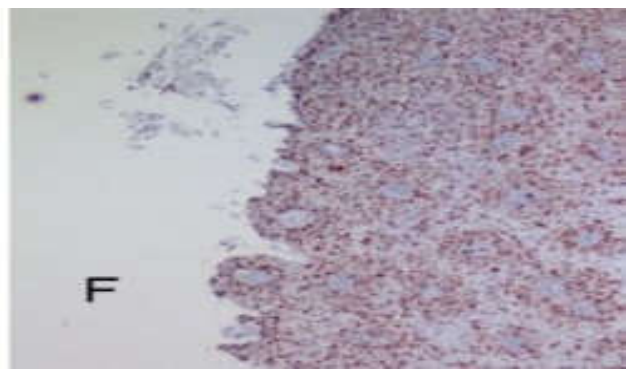

F) Section showing grade $3+$ (positive) immunohistochemical expression of Ki-67in moderately differentiated squamous cell carcinoma $(\mathrm{Ki}-67 ; \mathbf{x 4})$

\section{Discussion}

Cervical cancer ranks as the seventh most common cancer and the fourth most common cancer in females. ${ }^{[1]}$ In the present study, the mean age of cases of malignant cervical lesions was 53.9 years $(\mathrm{SD} \pm 11.28)$ while for premalignant lesions was 40 years $(\mathrm{SD} \pm 10.83)$. This study is in concordance with a previous study from India which has observed the mean age of incidence of cervical pre malignant and malignant lesions to be 39 years and 49 years with an age range of 31-40 years and 41-60 years respectively [7].

It was observed in our study that premalignant and malignant cervical lesions were associated with significantly higher rate of illiteracy $(70 \%)$, low socioeconomic status (84\%) and smoking (76\%) in comparison to control. This is usually related to less awareness about causes of cervical cancer and its prevention. In addition, poor personal hygiene and genitourinary infections may also be contributing factor to it. In our study we found that smoking habit (including both active and passive) was more commonly observed in cases than in controls ( $p$ value $<$ 0.001). Rouraet al have also observed that smoking status, duration and intensity contributes to a two times increased threat of developing in situ and invasive cervical cancer [8].

In addition, age of first sexual contact, first conception and high parity are also suggested to be important risk factor for cervical malignancy. Previous studies have also found them to be important and self-sufficient risk factors for cervical cancer $[9,10]$. The significantly increased positivity of HPV 16 expression in cases 
(including both pre malignant and malignant) supports the fact that HPV 16 is associated with cervical cancers in this hilly state of India also. The present study also showed that HPV 16 is uniformly present in cervical premalignant and malignant lesions and there is no difference in its expression with severity of the lesion. This is in concordance with previous study by Zouheiret al who have also observed that there is no significant difference in HPV detection rate between HSIL (high grade squamous intraepithelial lesion) and LSIL (low grade squamous intraepithelial lesion) or between HSIL and cervical cancer[11]. In the present study, it was found that maximum number of cases $(90 \%)$ were positive for Ki-67, amongst which $56 \%$ showed grade 3 positivity while all controls $(100 \%)$ were negative for Ki-67 expression.

It shows that $\mathrm{Ki}-67$ grading was significantly more in cases than in controls ( $\mathrm{p}$ value $<0.001$ ). Amongst the premalignant cases, maximum number $(66.7 \%)$ showed grade $1 \mathrm{Ki}-67$ expression while maximum malignant cases showed grade 3 positivity (68.3\%). This shows that grading of Ki-67 increases with the severity of the cervical lesions and may be used as an important immunohistochemical marker to determine the severity of lesion. An interesting finding that was observed in the present study was that $87.2 \%$ of the HPV 16 positive cases were also positive for Ki-67 expression which was statistically significantly higher in comparison to controls. However, this association of HPV 16 and Ki-67 did not depend on the severity of the cervical lesions.

This possible reason may be due to equivocal positivity of HPV 16 in premalignant and malignant cervical lesions. In addition, the number of cases included in the premalignant and malignant lesions was also less. Further, an important observation in our study was that $81.4 \%$ of total HPV 16 negative individuals (including cases and controls) were also negative for $\mathrm{Ki}-67$ and $82.9 \%$ of HPV 16 positive individuals were also positive for Ki-67.

This indicates that HPV16 infection is associated with proliferation of cervical epithelial cells which is indicated by Ki-67 proliferative marker expression and thus this interaction plays an important role in carcinogenesis of cervical cancer.

However an important limitation of the present study was that lesser number of cases were including in the study and therefore larger studies should be done to clearly establish the role of $\mathrm{Ki}-67$ as a biomarker in the routine diagnostic work up of cervical neoplastic lesions and its association with HPV 16.

\section{Original Research Article}

\section{Conclusion}

The study concludes that low socioeconomic status, low education status, smoking (either active or passive), early age of sexual contact, early age of first conception and high parity were associated with increased risk of cervical premalignant and malignant lesions in this region of India.

HPV 16 positivity is associated with positive expression of $\mathrm{Ki}-67$ and thus $\mathrm{Ki}-67$ plays an important role in carcinogenesis of cervical cancer in association of HPV16.

The increase of immuno-positivity of Ki-67 with the severity of lesions suggests its use in stratification of premalignant and malignant lesions of cervix.

\section{Authors' Contributions}

UA: Conception of study, acquisition, analysis and interpretation of data, drafting of manuscript

S.C.: Design of the study, analysis and interpretation of data, drafting of manuscript

UB: Analysis of data, clinical intellectual input

VS: Analysis of data and intellectual input

What this study adds to the existing knowledge? Ki67 plays an important role in carcinogenesis of cervical cancer in association with HPV 16. The increase of immunopositivity of Ki-67 with the severity of lesions suggests its use in stratification of pre malignant and malignant lesions of cervix.

Findings: Nil; Conflict of Interest: None initiated Permission from IRB: Yes

\section{References}

1. Ferlay J, Colombet M, Soerjomataram I, et al. Estimating the global cancer incidence and mortality in 2018: GLOBOCAN sources and methods. Int J Cancer. 2019 Apr 15;144(8):1941-1953. doi: 10.1002/ijc.31937. Epub 2018 Dec 6.

2. Kumar V, Abbas AK, Fausto N, Aster JC. Female genital tract. In: Kumar V, Abbas AK, Fausto N, Aster JC, editors. Robbins \&Cotran Pathologic basis of disease. 8th ed. Philadelphia (Pennsylvinia): Elsevier; 2010. p.1018-9.

3. Vasilescu F, Ceauşu M, Tănase C, Stănculescu R, Vlădescu T, Ceauşu Z. P53, p63 and Ki-67 assessment in HPV-induced cervical neoplasia. Romanian Journal of Morphology and Embryology. 2009; 50(3):357-61. 
4. Hwang SJ, Shroyer KR. Biomarkers of cervical dysplasia and carcinoma. J Oncol. 2012;2012:507286. doi: 10. 1155/ 2012/ 507286. Epub 2011 Oct 29.

5. Archana S, Eswari V, Prakash G. Ki-67 Expression in squamous intraepithelial lesions and carcinoma cervix by immuno-histochemistry. International Journal of Scientific Research. 2016; 5(8):204-7. doi: 10.15373 / 22778179

6. Yi W, Wang JL, Li XH, et al. [Correlations of highrisk human papillomaviral load to cervical intraepithelial neoplasia grades, expression of Ki-67 and P6ink 4a and follow-up]. Ai Zheng. 2008 May;27 (5): 520-4.

7. Bamanikar S, Baravkar D, Chandanwale S, Dharwadkar A, Paranjape S. Study of cervical cytology and its correlation with clinical and histopathological findings. Clinical Cancer Investigation Journal. 2016; 5(5): 403-8.doi: 10.4103/2278-0513.197869

\section{Original Research Article}

9. Roura E, Castellsagué X, PawlitaM, et al. Smoking as a major risk factor for cervical cancer and pre-cancer: results from the EPIC cohort. Int J Cancer. $2014 \mathrm{Jul}$ 15; 135(2):453-66. doi: 10.1002/ijc.28666. Epub 2014 Jan 6

10. Green J, Berrington de Gonzalez A, et al. Risk factors for adenocarcinoma and squamous cell carcinoma of the cervix in women aged 20-44 years: the UK National Case-Control Study of Cervical Cancer. Br J Cancer. 2003 Dec 1;89(11):2078-86. DOI:10. 1038/ sj.bjc.6601296.

11. Pandey A, Chandra S, Nautiyal R, Shrivastav V. Expression of $\mathrm{p} 16 \mathrm{INK} 4 \mathrm{a}$ and human papilloma virus 16 with associated risk factors in cervical premalignant and malignant lesions. South Asian J Cancer. 2018; 7 (4): 236-9. doi: 10.4103/sajc.sajc_118_17

12. Zouheir $\mathrm{Y}$, Fechtali $\mathrm{T}$, Elgnaui N. Human papillomavirus Genotyping and p16ink4a expression in cervical lesions: A combined test to avoid cervical cancer progression. Journal of Cancer Prevention. 2016; 21(2):121-5.

\section{How to cite this article?}

Agarwal U, Chandra S, Barua U, Shrivastava V. Expression of Ki 67 and human papilloma virus 16 with risk factors in cervical pre malignant and malignant lesions. Trop J Path Micro 2019;5(5):293-299.doi:10.17511/jopm.2019.i05.07. 